\title{
Lipidomic fatty acid profile and global gene expression pattern in mammary gland of rats that were exposed to lard-based high fat diet during fetal and lactation periods associated to breast cancer risk in adulthood
}

\author{
Fábia de Oliveira Andrade ${ }^{a}$, Sonia de Assis ${ }^{b}$, Lu Jin ${ }^{b}$, Camile Castilho Fontelles ${ }^{a}$, Luís Fernando Barbisan ${ }^{c}$, \\ Eduardo Purgatto ${ }^{\mathrm{a}}$, Leena Hilakivi-Clarke ${ }^{\mathrm{b}}$, Thomas Prates Ong ${ }^{\mathrm{a}, \mathrm{d}, *}$

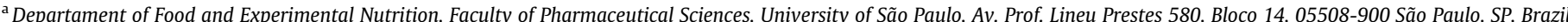 \\ ${ }^{\mathrm{b}}$ Department of Oncology, Georgetown University Lombardi Comprehensive Cancer Center, Research Building, Room E407, Georgetown University School of Medicine, 3970 \\ Reservoir Road NW, Washington, DC 20007, USA \\ ${ }^{\mathrm{C}}$ Department of Morphology, Botucatu Bioscience Institute, State University of São Paulo Botucatu, Distrito de Rubião Júnior, s/n. Rubião Júnior, 18618000 Botucatu, SP, Brazil \\ ${ }^{\mathrm{d}}$ Food Research Center (NAPAN), Av. Prof. Lineu Prestes 580, Bloco 14, 05508-900 São Paulo, SP, Brazil
}

\section{A R T I C L E I N F O}

\section{Article history:}

Received 29 December 2014

Received in revised form 5 June 2015

Accepted 23 June 2015

Available online 23 June 2015

\section{Keywords:}

Breast cancer

Animal fat

Fetal programming

Global gene expression

Lipidomic

DDN analysis

\begin{abstract}
A B S T R A C T
The persistent effects of animal fat consumption during pregnancy and nursing on the programming of breast cancer risk among female offspring were studied here. We have previously found that female offspring of rat dams that consumed a lard-based high-fat (HF) diet (60\% fat-derived energy) during pregnancy, or during pregnancy and lactation, were at a reduced risk of developing mammary cancer. To better understand the unexpected protective effects of early life lard exposure, we have applied lipidomics and nutrigenomics approaches to investigate the fatty acid profile and global gene expression patterns in the mammary tissue of the female offspring. Consumption of this HF diet during gestation had few effects on the mammary tissue fatty acids profile of young adult offspring, while exposure from gestation throughout nursing promoted significant alterations in the fatty acids profile. Major differences were related to decreases in saturated fatty acids (SFA) and increases in omega-6 polyunsaturated fatty acids (PUFAs), monounsaturated fatty acids (MUFAs) and conjugated linolenic acid (CLA) concentrations. In addition several differences in gene expression patterns by microarray analysis between the control and in utero or in utero and during lactation HF exposed offspring were identified. Differential dependency network (DDN) analysis indicated that many of the genes exhibited unique connections to other genes only in the HF offspring. These unique connections included Hrh1-Ythdf1 and Repin1-Elavl2 in the in utero HF offspring, and Rnf213-Htr3b and Klf5-Chrna4 in the in utero and lactation HF offspring, compared with the control offspring. We conclude that an exposure to a lard-based HF diet during early life changes the fatty acid profile and transcriptional network in mammary gland in young adult rats, and these changes appear to be consistent with reduced mammary cancer risk observed in our previous study.
\end{abstract}

(c) 2015 Elsevier Ireland Ltd. All rights reserved.
Abbreviations: CO, female rats exposed to control diet [AIN-93G] that has soy oil as fat source during gestation and lactation; DDN, differential dependency network; $\mathrm{G}$, female rats exposed to HF diet during gestation; GL, female rats exposed to HF diet during gestation and lactation; HF, lard-based high-fat; PCA, principal component analyses.

* Corresponding author at: Departamento de Alimentos e Nutrição Experimental, Faculdade de Ciências Farmacêuticas, Universidade de São Paulo, Av. Prof. Lineu Prestes 580, Bloco 14, 05508-900 São Paulo, SP, Brazil.

E-mail address: tong@usp.br (T.P. Ong).

\section{Introduction}

Consumption of fat is increasing world-wide [1]. From 19951997 to 2001-2003 the percentage of energy intake from total fat increased almost $2 \%$ globally and important contributors to this dietary change are vegetable oils and animal fat [2]. Of concern is the increase in animal fat intake as it is high in saturated fatty acids (SFA) [2], which is associated with many diseases, such as cardiovascular diseases, diabetes and neurodegenerative diseases [3-5]. 
However, the effects of dietary fats, including saturated fats on breast cancer risk are not clear yet [6-8]. Specifically for animal fat, contradictory effects were reported. In some studies, high consumption of animal fat, represented by red meat and dairy products, has been related to modestly elevated breast cancer risk $[6,9,10]$. On the other hand, many other epidemiologic studies have not observed an association between animal fat and SFA consumption and breast cancer risk $[7,8,11]$. Through a lipidomic analysis it was observed that patients with breast cancer present different fatty acids profile in the serum and erythrocyte membrane than cancer-free women, including changes in palmitic acid, stearic acid, linoleic acid and total free fatty acids, suggesting that altered lipid metabolism is an important feature in breast cancer $[12,13]$.

The amount and type of dietary fat consumption during gestation and/or lactation periods is another factor that can modulate breast cancer risk in the offspring [14,15]. Previous animal studies have shown that in utero exposure to diets rich in corn oil, containing high levels of omega-6 polyunsaturated fatty acids (PUFAs), increased the susceptibility to mammary carcinogenesis in adulthood $[16,17]$. In addition, maternal consumption during gestation and lactation of menhaden ( $n-3$ PUFA), canola ( $n-3$ and $n-6$ PUFAs and monounsaturated fatty acids [MUFAs]) or olive oil (MUFA)-based diets decreased chemically induced breast cancer development in the offspring [18-20]. It is suggested that early life exposure to dietary fat can modify the susceptibility to breast cancer in adult life through persistent modulation of gene expression $[21,22]$. Nutrigenomics analysis of global gene expression is an useful strategy to identify functionally relevant pathways involved in breast cancer susceptibility, modulated by nutritional exposures early in life [23].

We have previously shown that female offspring of rat dams consuming high amounts of lard (60\% fat-derived energy) during pregnancy, or during pregnancy and lactation, were at a reduced risk of developing mammary cancer [24]. In the group exposed to lard-based high fat (HF) diet only in utero all aspects of mammary tumorigenesis were reduced (latency to tumor appearance, tumor incidence, multiplicity and burden) compared with the control group. Offspring of dams consuming the lard-based HF diet both during pregnancy and lactation exhibited only reduced mammary tumor multiplicity, suggesting a lower protection [24]. To better understand these unexpected protective effects by early life lard exposure, we have applied a lipidomics and nutrigenomics approach to investigate the fatty acid profile and global gene expression patterns in the mammary tissue of adult female offspring of dams that consumed a lard-based HF diet during gestation or gestation and lactation periods.

\section{Material and methods}

\subsection{Experimental protocol}

The mammary tissues used in the present study were obtained from our previously completed study [24]. Briefly, before mating female Sprague-Dawley rats were divided into 3 groups $(n=20$ dams per group): (a) CO (female rats exposed to control diet [AIN-93G] that had soy oil as fat source during gestation and lactation; controls); (b) G (female rats exposed to lard-based HF diet during gestation and AIN-93G during lactation), and (c) GL (female rats exposed to lard-based HF diet during gestation and lactation). The HF diet is based on AIN-93G [25] with added lard replacing some carbohydrates. CO and HF diets contained $10 \%$ and $60 \%$ of total energy from fat, respectively. The distribution of fatty acids in the HF diet was $37 \%, 38 \%$ and $24 \%$ of SFA, MUFA and PUFA, respectively, while in the $\mathrm{CO}$ diet, the distribution of the same fatty acids was $17 \%, 27 \%$ and $55 \%$. During lactation, the diet of dams from $G$ group was switched to AIN93-G, while the diets of dams from CO and GL groups remained AIN93-G and HF, respectively. As previously described [24] caloric intake was not different $(P>0.05)$ among the dams in any of the diets groups ( $\mathrm{CO}, \mathrm{G}$ and $G L)$ during gestation and lactation, and body weight gain during pregnancy and body weight at the end of lactation were also not different among them. After weaning all female offspring consumed commercial laboratory chow (Nuvital, Brazil). The 7-week-old female offspring were euthanized using $\mathrm{CO}_{2}$ chamber and the mammary gland stored at $-80^{\circ}$ for further analysis. The experiments were approved by the Ethics Committee on Animal Experiments of the Faculty of Pharmaceutical Sciences, University of São Paulo (Protocol Number 283). The animal experiment has been described in detail before [24].

\subsection{Fatty acid lipidomics analysis}

Lipids were extracted from the 4th mammary gland obtained from 7-week-old female offspring of CO, G or GL groups ( $n=4$ per group) using Folch method. About $50 \mathrm{mg}$ of tissue was macerated with liquid nitrogen, mixed with $1 \mathrm{~mL}$ of chloroform:methanol (2:1); $25 \mu \mathrm{L}$ of PMSF; $10 \mu \mathrm{L}$ of $\mathrm{C} 19$ standard diluted in dichloromethane and incubated overnight at $4{ }^{\circ} \mathrm{C}$. After the incubation, water was added ( $5 \times$ volume), tissue was homogenized for $50 \mathrm{~min}$ and incubated again overnight at $4{ }^{\circ} \mathrm{C}$. The methanolic phase was then collected. Derivatization of fatty acids to methyl esters (FAMEs) was carried out according to the protocol described by Ichihara and Fukubayashi (2010) [26] with some modifications. The samples were injected $(1 \mu \mathrm{l})$ in split mode (5:1) at $250{ }^{\circ} \mathrm{C}$ in the GC/MS system (Agilent 6890 coupled to an Agilent 5973 Mass Selective Detector). The column was a DB-5MS capillary column $(30 \mathrm{~m} \times 0.25 \mathrm{~mm}$ inner diameter, $0.25 \mu \mathrm{m}$ film thickness; Agilent). The FAMEs were identified by comparison of their retention time to their respective standards, and a mass spectral survey was performed using the NIST Mass Spectral Library (2008). The analyses were performed in triplicate for each sample and each FAME was quantified based on curves made with authentic standards (Supelco, Inc). Supplementary Table 1 provides a list of all lipids that were analyzed in the mammary gland.

\subsection{Analysis of global gene expression in female offspring's mammary gland}

Total RNA was extracted from the 4th mammary glands obtained from 7-week old female offspring from CO, G or GL groups ( $n=5$ per group) using RNeasy Lipid Tissue Mini Kit (QIAGEN, USA) according to the manufacturer's protocol. RNA quality was confirmed using an Agilent 2100 Bioanalyzer and RNA 6000 LabChips, from which the RNA integrity numbers (RIN) were calculated. High quality total RNA was labeled and hybridized to Affymetrix Rat Genome 2302.0 GeneChip using the manufacturer's protocols. Expression data were normalized by the probe logarithmic intensity error (PLIER) method as implemented in Affymetrix expression console 1.2 (http://www.affymetrix.com/). Student $t$-test $P$-values and fold changes were calculated by comparing 30,000 transcripts and variants between $\mathrm{CO} \times \mathrm{G}, \mathrm{CO} \times \mathrm{GL}$ and $G \times G L$, with $P \leqslant 0.05$ (univariate, two tailed) and fold change $\geqslant 1.5$ identified as differentially expressed genes. Principal component analyses (PCA) was obtained with the data set to summarize the variation of gene expression under HF exposure on pregnancy, and pregnancy and lactation. For differential dependency network (DDN) analysis MATLAB and Cytoscape were used for analysis and visualization, respectively [27]. The parameters used for DDN analysis were $K=1, P$ value cutoff $=0.01$, threshold $=0.25$. Bio Function analysis of all significantly differentially 
expressed genes among groups was performed by Ingenuity pathway analysis (IPA).

\subsection{Validation of differently expressed genes in female offspring's mammary tissue}

Expression levels of target genes were measured using a 7900HT Fast Real-Time PCR System (Applied Biosystems) by Relative Standard Curve Method as described before [24]. Gapdh was used as the reference gene to normalize target gene expression. Primers were designed using IDT tool primer design (Supplementary Table 2). Results are expressed as mean \pm S.E.M, and all analyses were conducted with STATISTICA 8.0 (Statsoft, USA). One-way analysis of variance (ANOVA) followed by Duncan's post hoc was applied. For all data analysis, $P \leqslant 0.05$ was applied as the threshold for statistical significance.

\section{Results}

3.1. Mammary tissue lipid profile of 7-week old female offspring of $\mathrm{CO}$, $G$ and GL groups

The lipid profile of the mammary tissue clearly differentiated the female offspring of GL dams from $\mathrm{CO}$ and $\mathrm{G}$ offspring (Fig. 1a). These differences were mostly seen in the following fatty acids: SFAs stearic, myristic, lauric, behenic, heneicosylic and pentadecylic acid; MUFAs myristoleic, cis-13-octadecenoic, heptadecenoic and oleic; omega-3 PUFAs docosahexaenoic, eicosapentaenoic and linolenic acids; and omega-6 PUFAs dihomo- $\gamma$-linolenic acid, arachidonic, linoleic, eicosadienoic; and the conjugated linoleic acid (CLA) 10-trans, 12-cis- octadecadienoic (Fig. 1b). In addition, less notable differences were observed between the female offspring of G and CO dams (Fig. 1a), mainly in the SFAs lauric, myristic, heneicosylic, behenic, and lignoceric acids and omega-3 PUFA docosahexaenoic acid (Fig. 1b).

According to ANOVA test, 15 fatty acids showed different mammary gland concentrations among the $\mathrm{CO}, \mathrm{G}$ and $\mathrm{GL}$ female offspring groups (Fig. 2). More specifically, compared with CO group, the $G$ female offspring group presented higher $(P \leqslant 0.05)$ mammary gland levels of arachidonic acid $(n-6)$ and lower $(P \leqslant 0.05)$ levels of SFAs lauric and myristic fatty acids. The offspring of GL dams, in turn, presented higher $(P \leqslant 0.05)$ levels of stearic acid (SFA), myristoleic, cis-10-heptadecenoic, cis-13-octadecenoic, oleic and cis-11-eicosenoic acids (MUFA), dihomo- $\gamma$-linolenic acid, linoleic, arachidonic and eicosadienoic acids (omega-6), and trans-10, cis-12-octadecadienoic (CLA) fatty acids than the CO group. They also had lower $(P \leqslant 0.05)$ levels of SFAs lauric, myristic, heneicosylic and behenic fatty acids (Fig. 2). Compared with the $G$ group, the offspring from GL group presented higher $(P \leqslant 0.05)$ levels of stearic acid (SFA), myristoleic, cis-10-heptadecenoic, cis-13-octadecenoic and cis-11-eicosenoic acids (MUFA), dihomo- $\gamma$-linolenic acid, linoleic and eicosadienoic acids (omega-6), and trans-10, cis-12-octadecadienoic (CLA) fatty acids, as well as lower $(P \leqslant 0.05)$ levels of lauric and myristic (SFA) fatty acids (Fig. 2).

\subsection{Comparison of global gene expression in the mammary tissue of female offspring of $\mathrm{CO}$ and $\mathrm{G}$ dams}

We identified 51 genes as significantly differentially expressed in the mammary tissue between the female offspring from $\mathrm{CO}$ and $\mathrm{G}$ groups (Fig. 3a). Compared with the $\mathrm{CO}$, offspring from the $G$ group presented 25 downregulated genes and 26 upregulated genes. PCA of the differentially expressed genes separated the experimental samples from the $\mathrm{CO}$ and $\mathrm{G}$ groups into two distinct clusters (Fig. 3b). The differentially expressed genes are involved in important pathways related to carcinogenesis such as cell growth and proliferation, cellular function and maintenance, cellular development, cell-to-cell signaling and interaction, cell signaling, nucleic acid metabolism, cell death and survival (Fig. 3c; Supplementary Table 3). Genes involved in carbohydrate metabolism were also significantly differentially expressed between the $\mathrm{CO}$ and $\mathrm{G}$ groups.

\subsection{Comparison of global gene expression in the mammary tissue of female offspring of $\mathrm{CO}$ and GL dams}

We identified 101 genes as significantly differentially expressed in the mammary tissue between the female offspring from $\mathrm{CO}$ and GL groups (Fig. 4a). Compared with the CO, offspring from the GL (a)

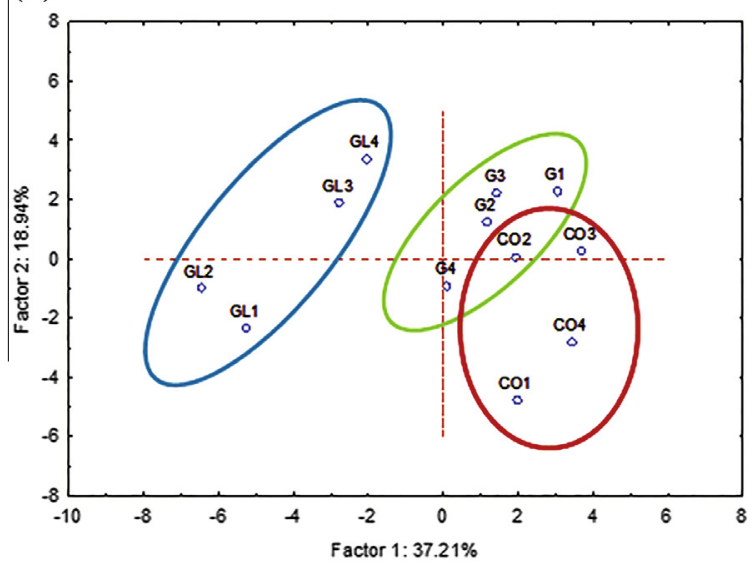

(b)

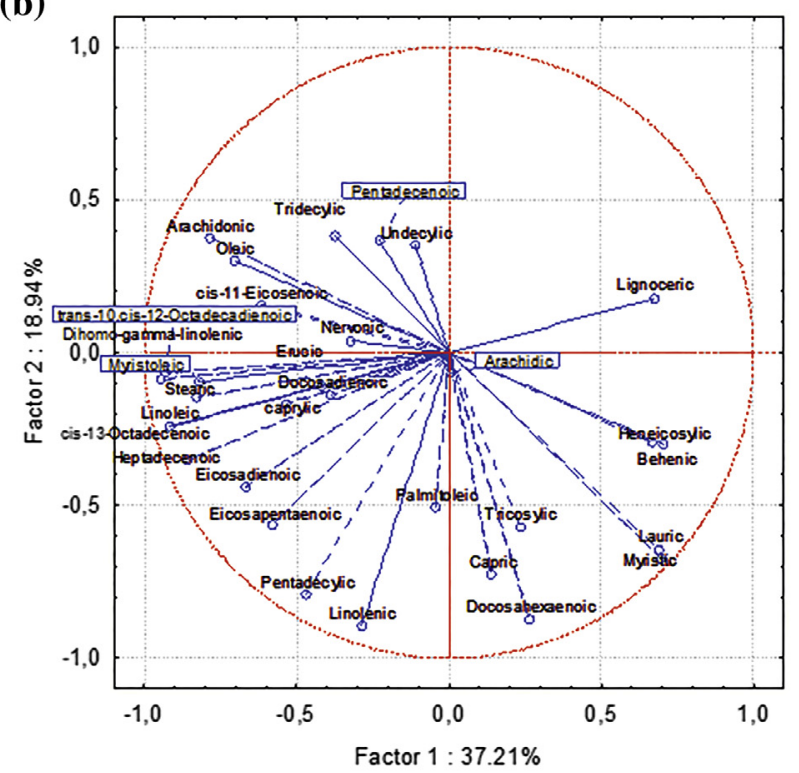

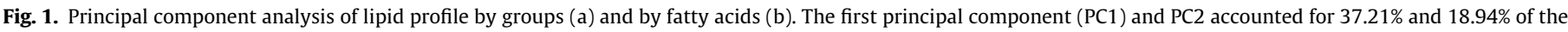
variation, respectively. CO: control group; G: in utero high fat exposed group; GL: in utero and during lactation high fat exposed group. 


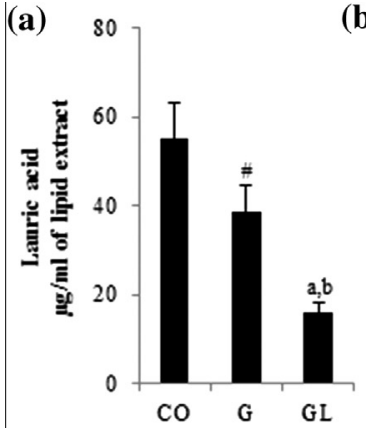

(f)
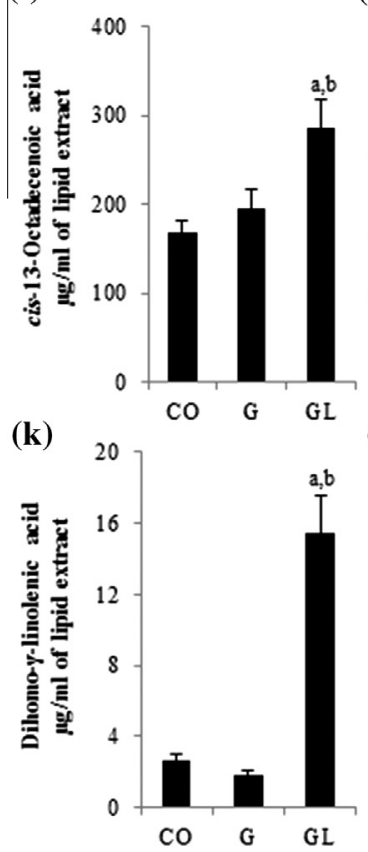

(b)

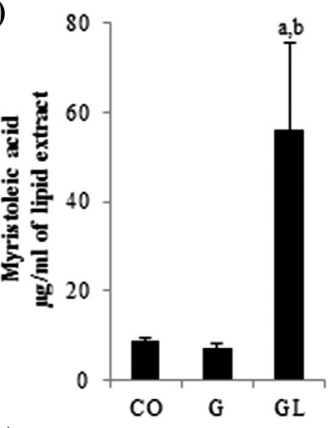

(g)

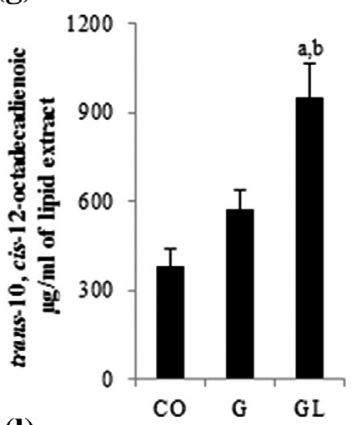

(l)

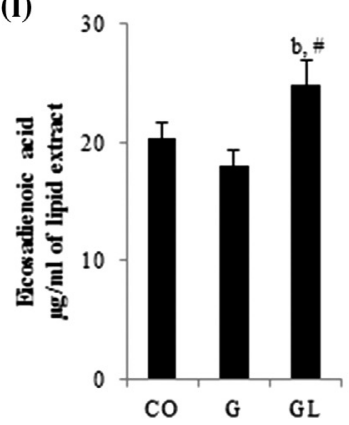

(c)

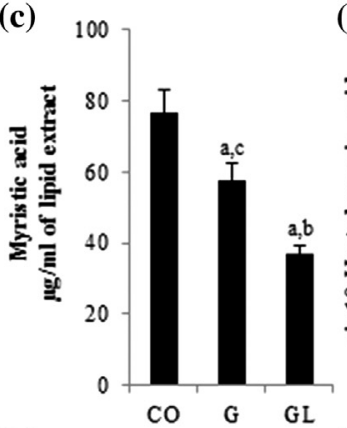

(h)

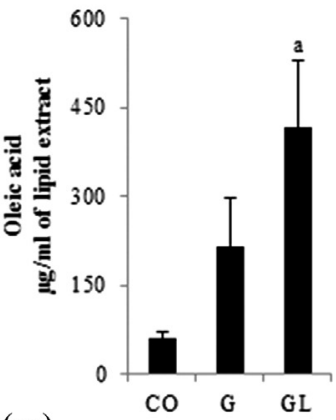

(m)

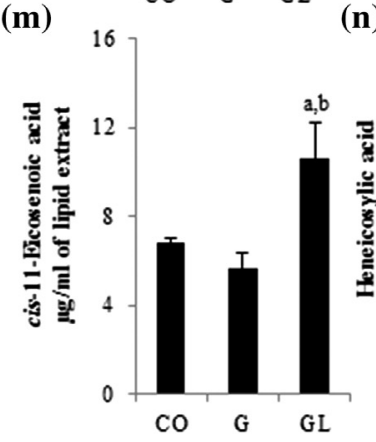

(d)

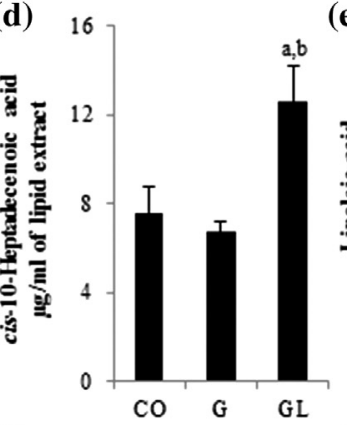

(i)

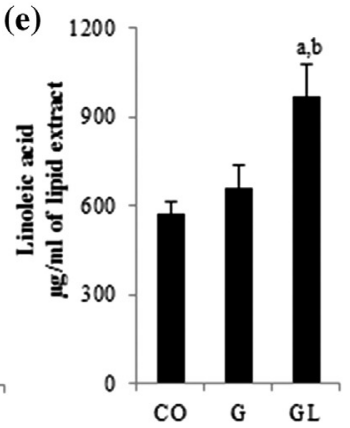

(j)
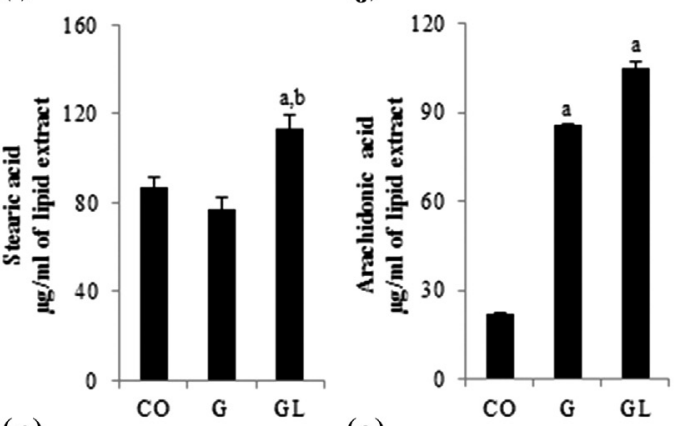

(o)

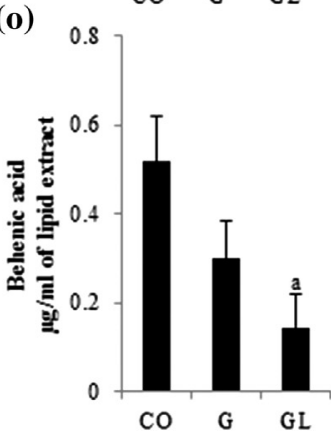

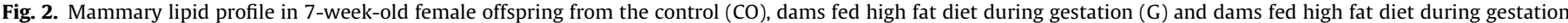

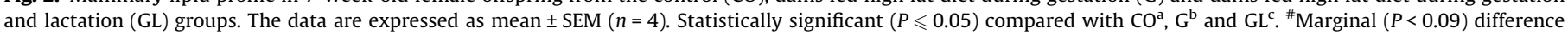
compared with $\mathrm{CO}$ according to ANOVA followed by the Duncan test.

group presented 46 downregulated genes and 55 upregulated genes. Because GL group offspring presented lower protection against mammary tumor development compared with $\mathrm{G}$ group offspring, the total number of differentially expressed genes is not directly linked to mammary cancer risk. Rather, the higher number of changes could just be a reflection of longer exposure to the lard-based HF diet. PCA of the differentially expressed genes separated the samples into two distinct clusters discriminating the GL group from the CO group (Fig. 4b). The differentially expressed genes are involved in important pathways related to development and carcinogenesis such as cancer, tumor morphology, cell cycle, organ development, tissue development, cell death and survival (Fig. 4c, Supplementary Table 4). Genes involved in lipid and carbohydrate metabolisms were also significantly differentially expressed between the CO and GL groups.

\subsection{Comparison of global gene expression in the mammary tissue of female offspring of $G$ and GL dams}

Although our previous study found that both the G and GL offspring exhibited lower susceptibility to mammary tumorigenesis than the control CO offspring [24], we identified 100 genes as significantly differentially expressed in the mammary tissues between the female offspring from $G$ and GL groups (Fig. 5a).
Compared with the G, offspring from the GL group presented 83 downregulated genes and 17 upregulated genes. PCA of the differentially expressed genes separated the samples between the GL and $G$ groups into two distinct clusters (Fig. 5b). The differentially expressed genes are involved in cancer, tumor morphology, cellular development, cellular growth and proliferation, tissue development and DNA replication, recombination and repair (Fig. 5c; Supplementary Table 5). Genes involved in lipid and carbohydrate metabolisms were also significantly differentially expressed between the $G$ and GL groups.

\subsection{DDN analysis between $C O$ and $G$ groups}

DDN was used to detect statistically significant topological changes in transcriptional networks between $\mathrm{CO}$ and $\mathrm{G}$ offspring [27]. According to this analysis, the transcriptional network changes in offspring exposed to HF diet in utero ( $G$ group) (Fig. 6a) comprised of 9 connections (green connections) that exist only in G samples, and 7 connections (red connections) that exist only in CO samples. We then performed RT-PCR analysis to verify that the genes in the connections were differentially expressed and observed that Hrh1 connecting to Ythdf1, and Repin1 connecting to Elavl2 were significantly up-regulated in the offspring of dams fed HF during pregnancy (G group) (Fig. 7). 
(a)

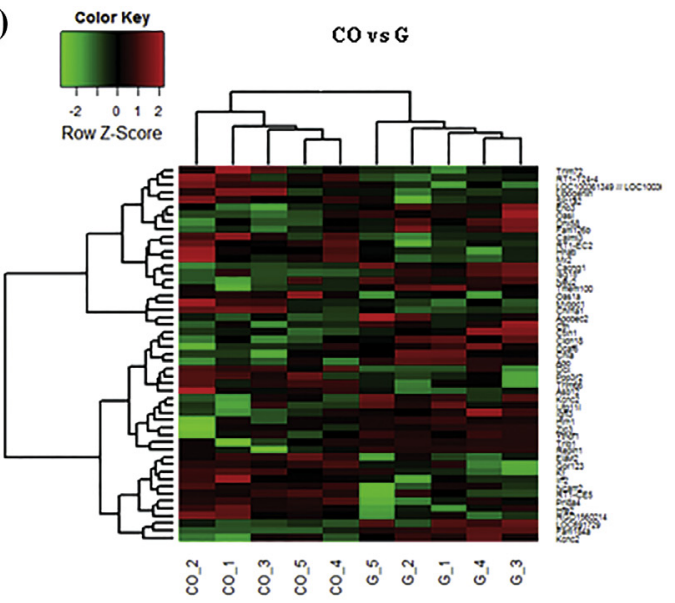

(b)

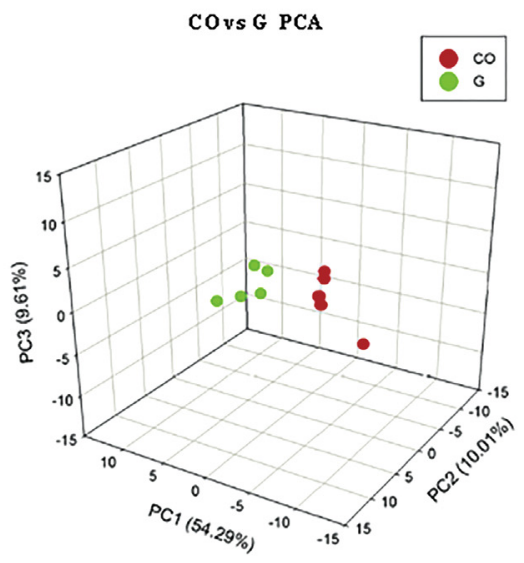

(c)
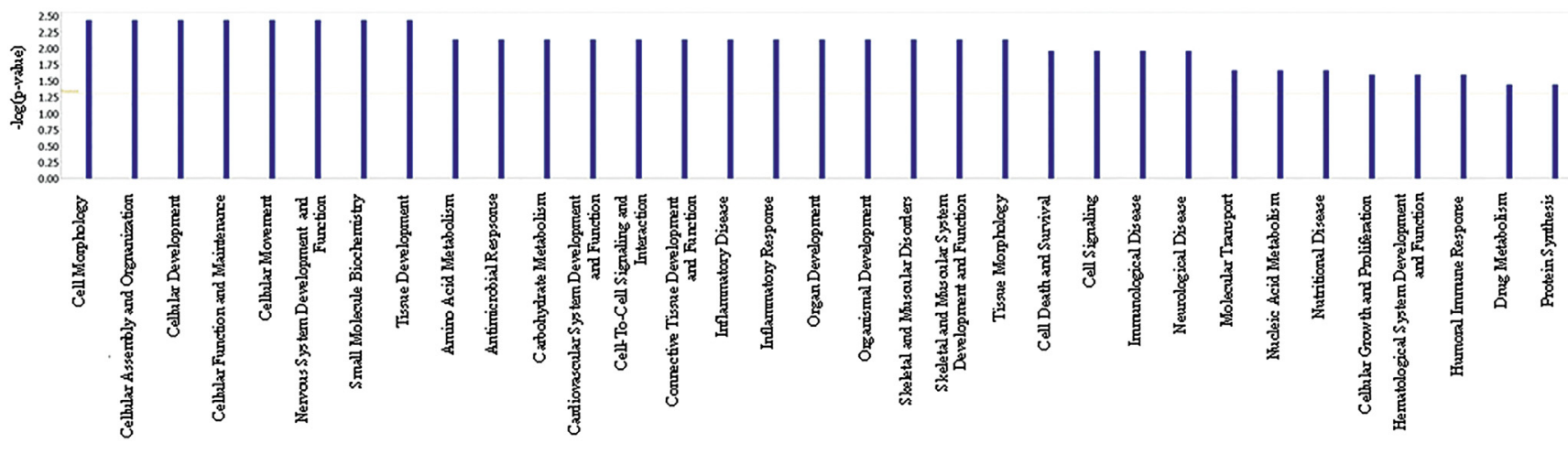

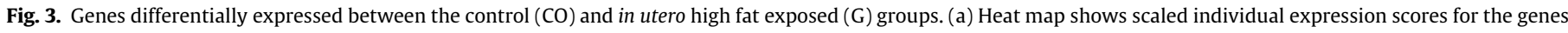

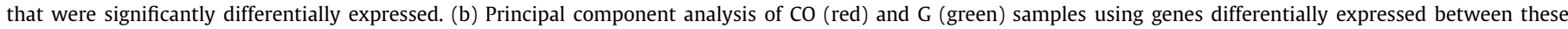

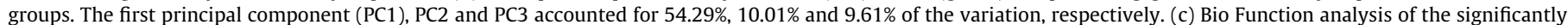

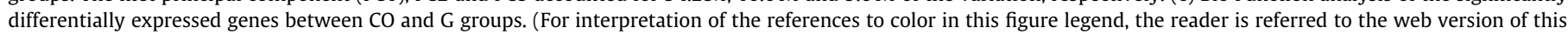
article.)

\subsection{DDN analysis between $C O$ and GL groups}

According to DDN analysis, the transcriptional network changes in offspring exposed to HF diet in utero and nursing (GL group) (Fig. 6b) comprised 2 connections (green connections) that exist only in GL samples and 10 connections (red connections) that exist only in CO samples. We observed for the first time that Rnf213 and $H t r 3 b$, as well as, Klf5 and Chrna4 are connected in the mammary gland just in the condition of exposure to HF diet in in utero and lactation periods.

\subsection{DDN analysis between $G$ and GL groups}

According to DDN analysis, the transcriptional network changes in offspring exposed to HF diet in utero and nursing (GL group) compared with $\mathrm{G}$ group (Fig. $6 \mathrm{c}$ ) comprised 3 connections (red connections) that exist only in $\mathrm{G}$ samples and 6 connections (green connections) that exist only in GL samples. Examples of new interactions that were observed only on the latter group include: Agpat3/Ydjc, Mycbp2/S100g and Tmcc1/Ubash3b/Lemd2/Tpo and another interesting connection that occurred just in $G$ group included Fhl1/Crkrs.

\subsection{Verification of differential gene expression}

We then determined if any of the genes identified in the microarray analysis were differentially expressed by RT-PCR. For that purpose, six genes that were differentially expressed in the microarray analysis were randomly chosen to be studied: Hrh1, Repin1, Stra6, Tlr1, Crkrs and Pam. In the offspring of G group, Hrh1 $(P \leqslant 0.05)$ and Repin1 $(P=0.08)$ were upregulated, compared with the control group, while in the offspring of GL group a marginal increase in Stra6 $(P=0.09)$ was seen (Fig. 7). Crkrs was not affected, compared with the offspring of $\mathrm{CO}$ group, but the offspring of GL group exhibited significantly lower expression of this gene than the G group (Fig. 7). Expression of Pam and Tlr1 in the offspring of $G$ and GL groups presented no statistical significance $(P>0.05)$.

\section{Discussion}

We have previously shown that increased maternal consumption of animal fat during pregnancy, or pregnancy and lactation, reduced female offspring's susceptibility to mammary cancer [24]. In the present study we applied lipidomics and nutrigenomics approaches to better understand how early life animal fat exposure might provide protection against later development of breast cancer.

Although the effects on breast cancer programming in offspring of dams consuming different types of fatty acids during pregnancy have been characterized, no information is available on the impact of such exposures on the lipidomic profile in the offspring's mammary glands. According to our results, exposure to a lard-based HF diet during gestation affected the mammary tissue fatty acid 
(a)

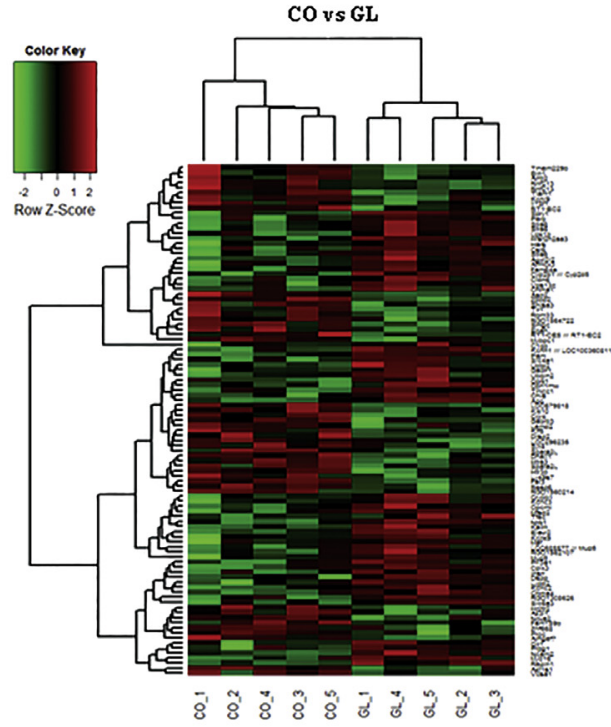

(b)

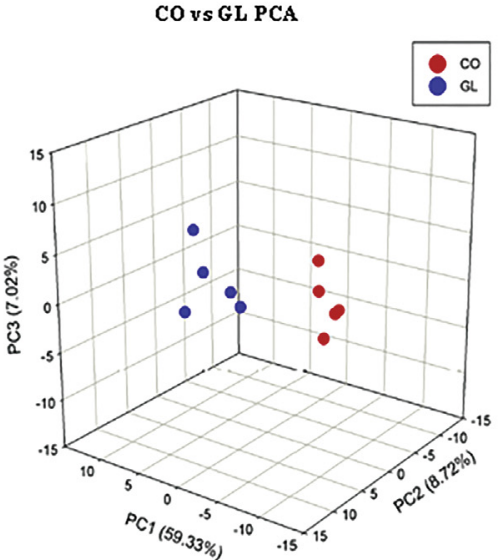

(c)

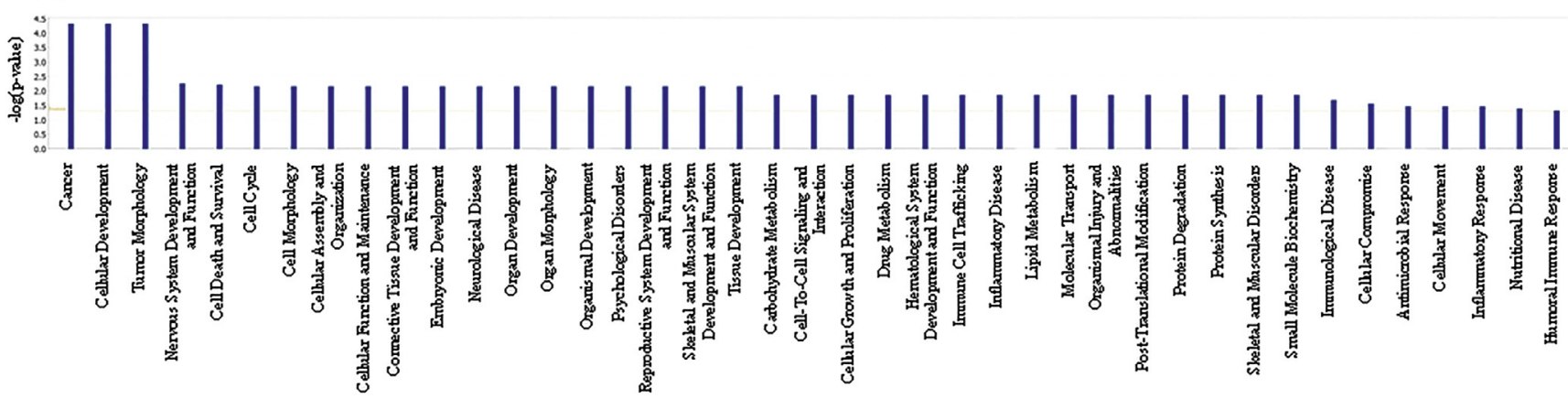

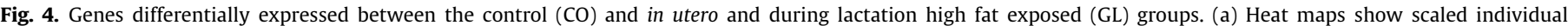

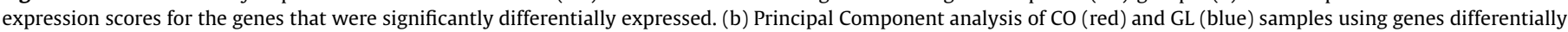

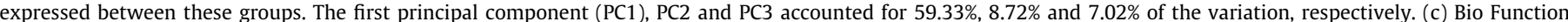

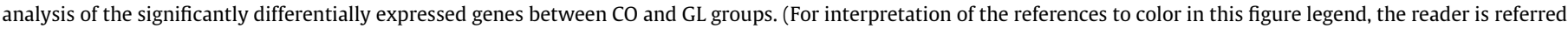
to the web version of this article.)

profile of adult offspring, and even more drastic changes were seen in the mammary glands on the offspring of dams consuming HF diet during both pregnancy and lactation. Since we previously [24] observed that the protection against breast cancer was stronger in the offspring exposed to the lard-based HF diet only in utero compared with the offspring exposed to this diet both in utero and lactation, the number of differences in the fatty acid profile is not directly linked to protection against breast cancer. Rather, it is consistent with the longer exposure to this diet.

Our findings of reduced SFA levels in rats with reduced mammary cancer risk are consistent with reports of some clinical studies that have linked increased serum and adipose tissue SFA concentrations to higher breast cancer risk $[12,28]$. Increased levels of MUFA (oleic, cis-10-heptadecenoic, cis-13-octadecenoic and cis-11-eicosenoic acids) and the CLA trans-10, cis-12-octadecadienoic acid may be associated with the programming effect of early life exposure to a lard-based HF diet and subsequent decreased susceptibility to mammary carcinogenesis in adulthood. Oleic acid is the main component of the Mediterranean diet and it has been shown to possess protective actions against breast cancer [29]. Results from a clinical study indicated that increased levels of oleic acid in the adipose breast tissue were associated with a decreased risk for the disease [30]. Olive oil-based diet consumption for 5 weeks prior and throughout gestation and lactation decreased chemically-induced mammary cancer development in the offspring [19]. Many in vitro and in vivo studies link high levels of
CLA to reduced breast cancer risk, and trans-10, cis-12-octadecadienoic acid has been proposed to acts as a chemopreventive agent against breast cancer [31]. Increased levels of omega-6 PUFA in the mammary tissue, in contrast, are not in agreement with findings showing that total omega-6 PUFA serum and adipose tissue (buttock) levels are positively associated with breast cancer [12,32]. Higher adipose tissue concentrations of linoleic and arachidonic acids were also associated with increased breast cancer risk $[29,33]$. In addition, maternal consumption during gestation of corn oil, a source of omega-6 PUFA, increased susceptibility to mammary carcinogenesis among female offspring [16]. These earlier studies have not taken into consideration the possibility that in combination with reduced levels of saturated fatty acids and increased levels of MUFA, high n-6 PUFA levels in the mammary tissue may not affect breast cancer risk.

Few studies have evaluated the effects of early life nutrition on global gene expression in adulthood, especially in the context of programming for later susceptibility to develop breast cancer. Exposure to high fat diets (butter, olive and safflower-based oils; $39 \%$ of energy from fat) in utero and through 50 days of age significantly altered the expression of genes associated with increased cell proliferation (Cyclin B1 and Cyclin A2), in the mammary glands of adult rats [22]. Pups fed either low-fat omega-3PUFA (16\% energy from fat) or high-fat omega-3 PUFA diet (39\% energy from fat) during prepubertal period (between postnatal days 5 and 24) showed decreased and increased carcinogen-induced mammary 
(a)

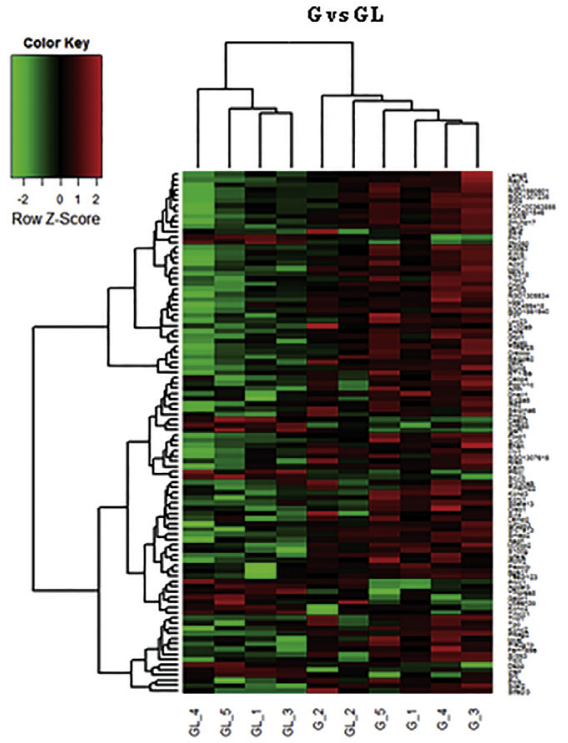

(b)

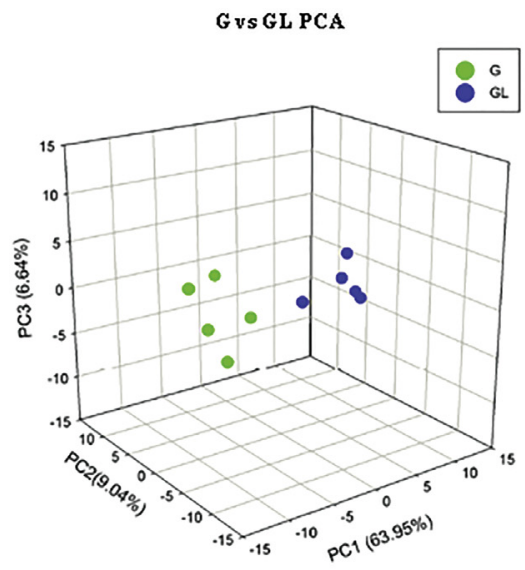

(c)

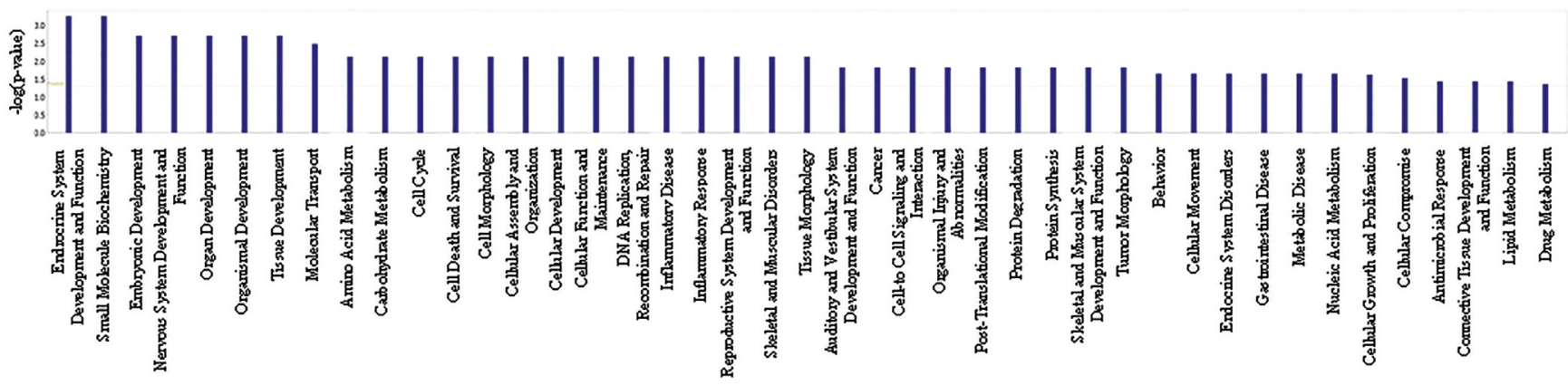

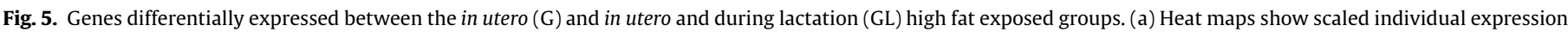

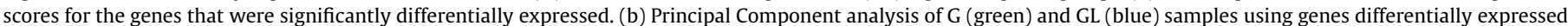

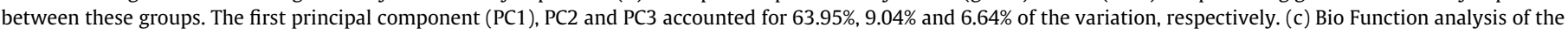

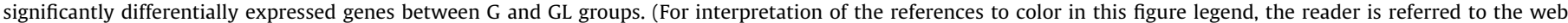
version of this article.)

tumorigenesis, respectively [34]. The protective effects were associated with upregulation of antioxidant genes, including thioredoxin and heme oxygenase in mammary glands [23]. In the present study, alterations in gene expression were also evaluated in the normal mammary gland, before breast cancer initiation, to investigate if the risk of developing this disease can be predicted from a gene signature.

We attempted to verify changes in the expression of multiple genes identified in the microarray analysis, but not all were differentially expressed when assessed using RT-PCR assay. Among the genes that were confirmed were Hrh1 and Repin1 that were upregulated in the mammary glands from offspring of dams fed HF lard diet during pregnancy. Histamine receptor 1 (Hrh1) is involved in liberating arachidonic acid from phospholipids and in the development of various aspects of the antigen-specific immune responses [35]. Elevated expression of Hrh1 has been associated with reduced tumorigenicity of human ovarian cancer cell (OV90) [36]. Replication initiator 1 (Repin1) regulates the expression of genes involved in adipogenesis, lipid droplet formation and fusion, and glucose and fatty acid transport in adipocytes [37]. Future studies are needed to determine if changes in the expression of these two genes that both affect lipid metabolism are causally related to reduced breast cancer risk in the offspring exposed to lard-based HF during fetal development.
Stra6 and Pam genes were upregulated and Tlr1 was downregulated in the mammary glands of animals that were exposed to HF diet both in utero and during nursing compared with control rats, although the differences did not reach statistical significance. Stimulated by retinoic acid 6 (Stra6) induces cellular internalization of retinol and is associated with anti-cancer actions of retinoids [38]. Stra6 is upregulated by DNA damage and plays a role in mediating p53-induced cell death [38]. These actions of Stra6 are consistent with lower mammary tumor multiplicity in the offspring of dams consuming HF diet during pregnancy and lactation [24]. Peptidylglycine alpha-amidating monooxygenase (PAM) is the rate-limiting enzyme in the modification of secretory peptides through C-terminal $\boldsymbol{\alpha}$-amidation [39]. It has a catalytic role by producing amidated product peptides and a non-catalytic role by affecting cytoskeletal organization, vesicular trafficking and secretion and it is sensible to ambient copper levels [40]. Although PAM is expressed in MCF-7 and ZR-75-1 human breast cancer cell lines [41], its role in cancer remains to be established. Toll-like receptor 1 (Tlr1) is member of a family of genes that mediates the production of cytokines necessary for the development of effective immunity. In general, higher expression of TLRs promotes inflammation and cancer cell survival [42]. Reduced expression of Tlr1 in the HF exposed GL offspring could be related to their reduced mammary tumorigenesis. 
(a)

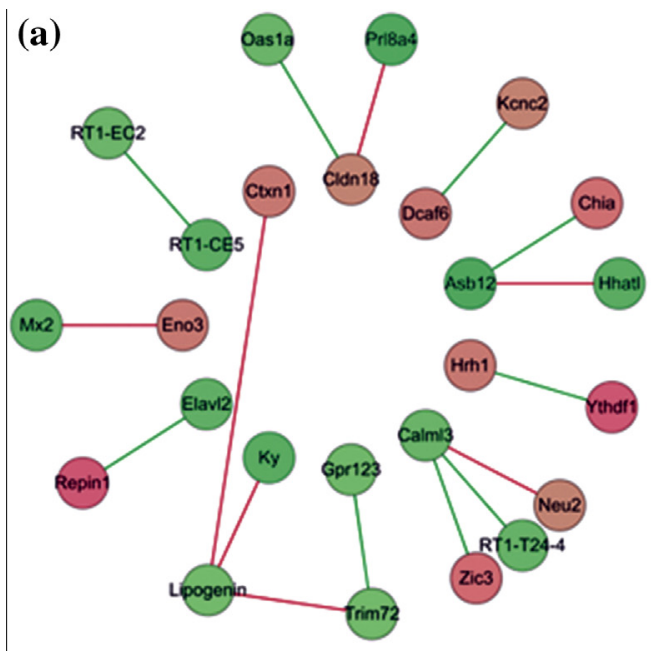

(b)

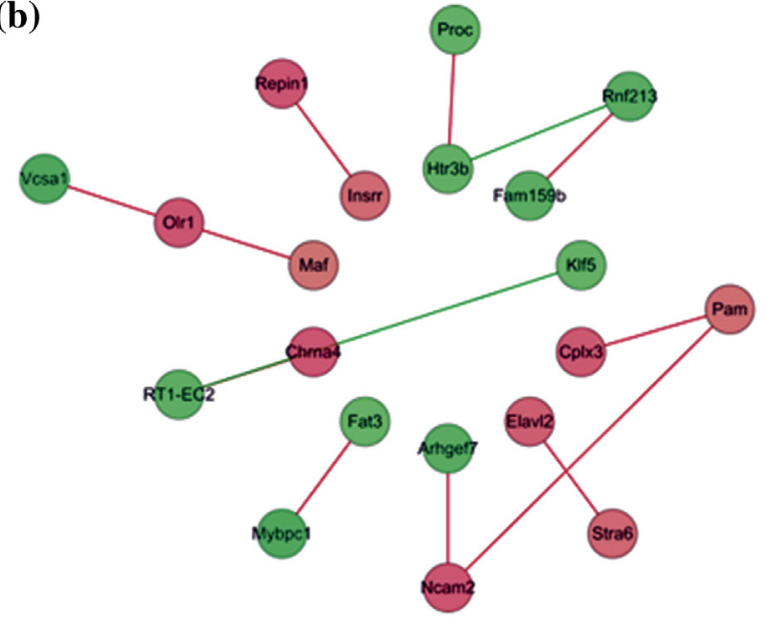

(c)
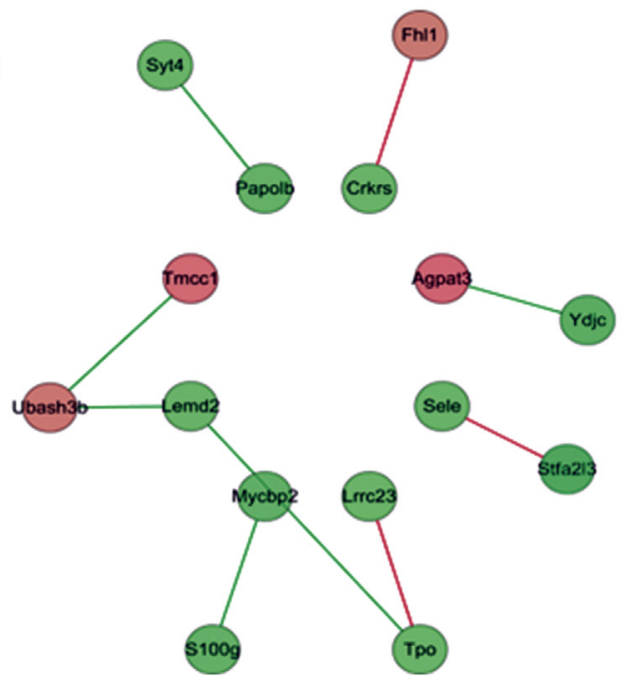

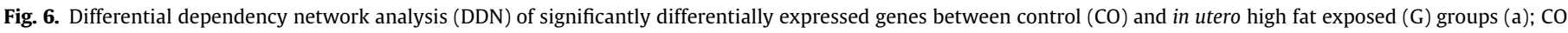

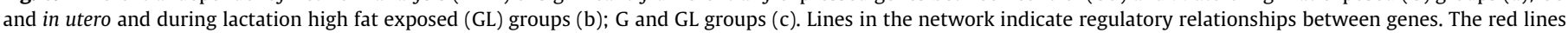

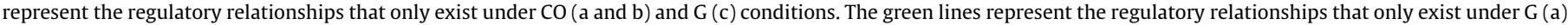

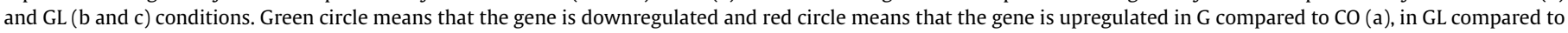
$\mathrm{CO}$ (b) and in GL compared to G (c). (For interpretation of the references to color in this figure legend, the reader is referred to the web version of this article.)

To help us to understand how the observed signaling changes might explain the reduced susceptibility to breast cancer among offspring of dams fed lard-based HF diet during pregnancy, or during pregnancy and lactation, the microarray data were subjected to DDN analysis. This analysis is a tool to detect unique connections in transcriptional networks present for example only in an experimental or control group [27]. In the present study, DDN analysis suggested new connections between Hrh1 and Ythdf1 and between Repin 1 and Elavl2 in the mammary glands of $\mathrm{G}$ offspring exposed to a HF diet only during fetal development. Both Hrh1and Ythdf1 were upregulated in mammary gland of rats exposed to HF in utero compared with controls. As described above, Hrh1 is involved in regulating omega-6 fatty acids release and immune functions [35,43]. Ythdf1 modulates RNA degradation in a N6-methyladenosine $\left(\mathrm{m}^{6} \mathrm{~A}\right)$ dependent manner [44]. Targets of this protein family include genes that are involved in cell metabolism, death and survival [44], and linked to body fat mass and obesity [45].

Repin1 was also upregulated, but its signaling partner, Elavl2 (also called $\mathrm{HuB}$ ) was down-regulated in the $\mathrm{G}$ offspring. As described above, Repin1 regulates fatty acid transport and is proposed to serve as a target to inhibit obesity and reverse insulin resistance [36]. The Hu proteins, in turn, are RNA-binding proteins that are involved in RNA metabolism, including in translation, and stability [46]. It's connection to cancer is not known, but another Hu protein Elavl1/HuR allows survival of tumor cells by activating tumor-promoting genes, such as VEGF [47]. It remains to be determined whether the connections between Hrh1 and Ythdf1 and between Repin 1 and Elavl2 are related to reduced mammary tumorigenesis in the offspring of dams fed-lard-based HF diet during pregnancy.

We also observed new connections that occur only in the offspring of dams fed a HF lard diet during pregnancy and lactation, compared with the control group, such as interactions between Rnf213 and Htr3b, as well as among Klf5 and Chrna4. Rnf213 and $H t r 3 b$ were both downregulated in the GL group. Rnf213 encodes a protein with ring finger domain and it is involved in chromosomal arrangement with c-Myc and ALK in anaplastic large cell lymphoma, and with SLC26A11 in chronic myeloid leukemia [48-50]. $\mathrm{Htr} 3 \mathrm{~b}$ is a serotonin receptor expressed in the central and peripheral nervous system, but it can also be expressed in other cells [51]. Its relation to cancer process has not been studied, but $H t r 3 b$ is an effective target in preventing chemotherapy-induced nausea and vomiting [52]. Klf5 was downregulated and Chrna4 was upregulated in the GL offspring. Kruppel-like factor 5 (Klf5) is a transcription factor that regulates cell proliferation by downregulating tumor suppressor p21 and stimulating cyclin D1 
(a)

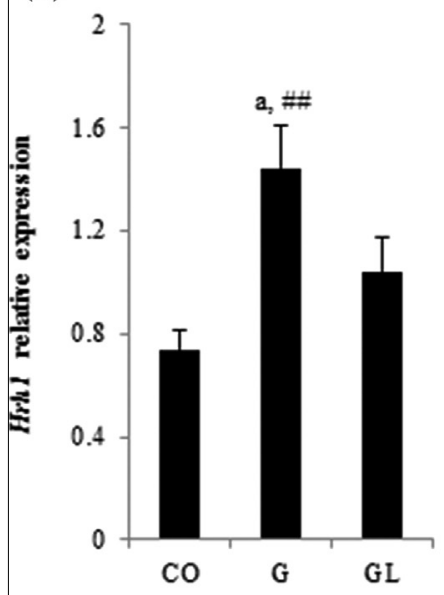

(d)

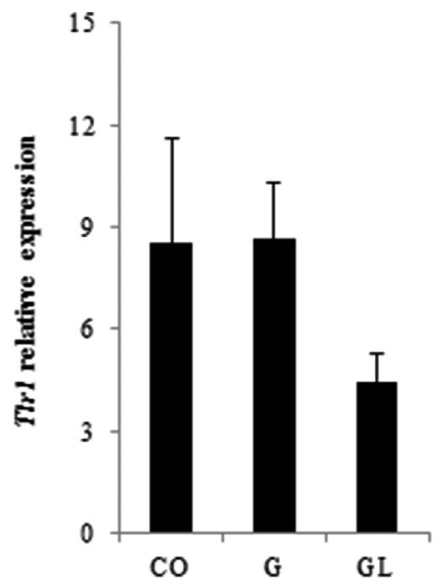

(b)

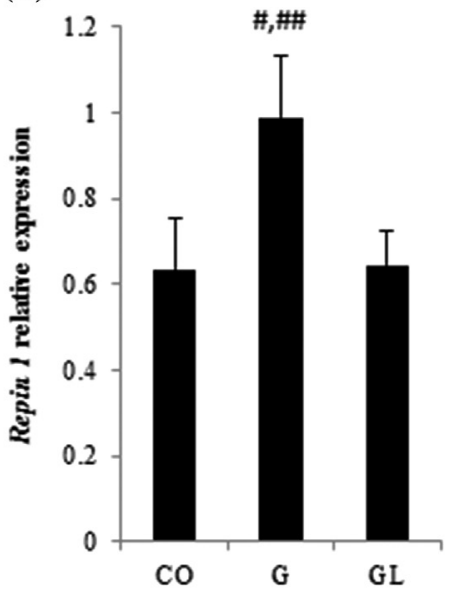

(e)

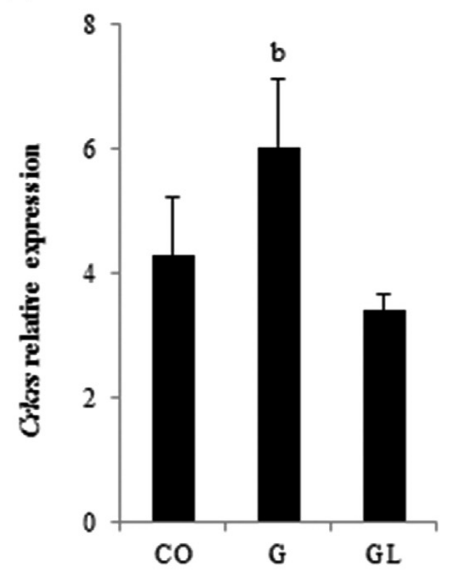

(c)

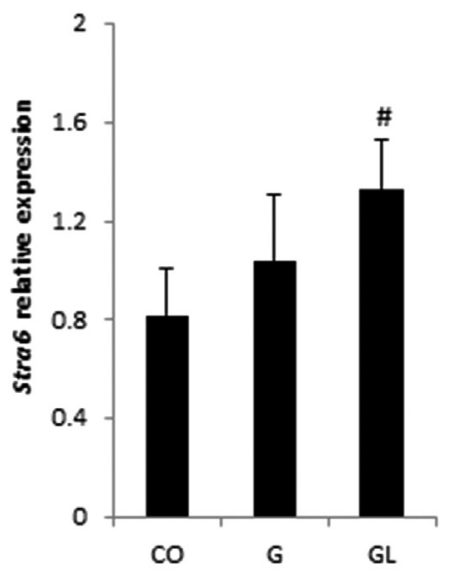

(f)

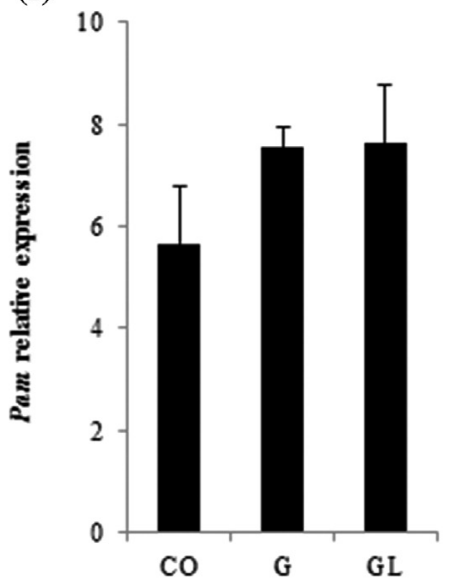

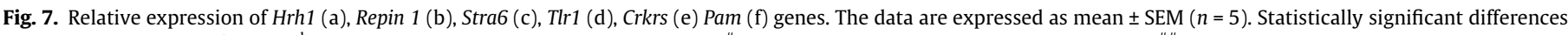

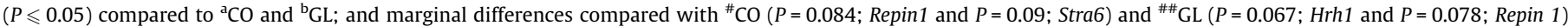
according to ANOVA followed by the Duncan test or Student $t$ test (Stra6 and Crkrs).

[53,54]. Further, elevated expression of Klf5 is proposed to be a biomarker of poor breast cancer prognosis [55]. Chrna4 encodes a nicotinic acetylcholine receptor which participates in the predisposition for preneoplastic lesions and emergence of lung carcinomas [56]. On the other hand, silent polymorphism in exon 5 in Chrna4 is associated to high levels oxidative DNA damage [57]. Additional studies are needed to evaluate the significance of these connections and the possible effects on mammary tumorigenesis.

We also investigated differences in gene signaling connections in the mammary glands of offspring exposed to HF diet only in utero or both in utero and during lactation. In the first group, Fhl1 (down-regulated) and Crkrs (upregulated) formed a connection. Fhl1 inhibits estrogen receptor $\alpha$ (ER- $\alpha$ ) phosphorylation and causes repression of translation and transcription of ER-responsive genes [58]. Crkrs regulates the expression of DNA damage response genes, including BRCA1 [59]. The GL group presented specific gene networking among Agpat3/Ydjc, Mycbp2/S100g and Tmcc1/Ubash3b/Lemd2/Tpo. Among their functions are regulation on biosynthesis of phospholipids (Agpat3), carbohydrate metabolism (Ydjc), mTOR signaling (Mycbp3) and organization of endoplasmic reticulum membrane (Tmcc1). At present time we can only conclude that these differences in gene expression are seen, but it is not known whether they are causally involved in explaining differences in mammary tumorigenesis among offspring exposed to HF lard diet during fetal period or in utero and postnatally during nursing.
We conclude that an exposure to a lard-based HF diet during early life permanently changes the fatty acid profile and transcriptional network in the mammary gland, but more studies are needed to determine a causality between the lipidomic and gene expression changes and the observed reduced susceptibility to breast cancer in adulthood [24]. Timing of exposure to HF diet differentially impacted all these outcomes, reinforcing the concept of different developmental susceptibility windows.

\section{Financial support}

This study was supported by Fundação de Amparo à Pesquisa do Estado de São Paulo (FAPESP; 2010/11742-0; 2011/23259-4; 2012/03330-9).

\section{Transparency Document}

The Transparency document associated with this article can be found in the online version.

\section{Acknowledgment}

This work was supported by Grant 2011/23259-4 and scholarships 2010/11742-0 and 2012/03330-9, São Paulo State Research Foundation (FAPESP - Brazil). 


\section{Appendix A. Supplementary data}

Supplementary data associated with this article can be found, in the online version, at http://dx.doi.org/10.1016/j.cbi.2015.06.035.

\section{References}

[1] M. Vadiveloo, M. Scott, P. Quatromoni, P. Jacques, N. Parekh, Trends in dietary fat and high-fat food intakes from 1991 to 2008 in the Framingham Heart Study participants, Br. J. Nutr. 111 (4) (2014) 724-734, http://dx.doi.org/ 10.1017/S0007114513002924.

[2] P. Wolmarans, Background paper on global trends in food production, intake and composition, Ann. Nutr. Metab. 55 (1-3) (2009) 244-272, http:/ dx.doi.org/10.1159/000229005.

[3] A.M. Salter, Dietary fatty acids and cardiovascular disease, Animal 7 (Suppl 1) (2013) 163-171, http://dx.doi.org/10.1017/S1751731111002023.

[4] C. Paquet, S.L. Propsting, M. Daniel, Total n-3 fatty acid and SFA intakes in relation to insulin resistance in a Canadian First Nation at risk for the development of type 2 diabetes, Public Health Nutr. 17 (6) (2014) 1337-1341, http://dx.doi.org/10.1017/S1368980013000542.

[5] N.D. Barnard, A.E. Bunner, U. Agarwal, Saturated and trans fats and dementia: a systematic review, Neurobiol. Aging 35 (Suppl 2) (2014) S65-S73, http:// dx.doi.org/10.1016/j.neurobiolaging.2014.02.030.

[6] B.F. Boyd, J. Stone, K.N. Vogt, B.S. Connelly, L.J. Martin, S. Minkin, Dietary fat and breast cancer risk revisited: a meta-analysis of the published literature, $\mathrm{Br}$. J. Cancer 89 (9) (2003) 1672-1685.

[7] T.J. Key, P.N. Appleby, B.J. Cairns, R. Luben, C.C. Dahm, T. Akbaraly, E.J. Brunner, V. Burley, J.E. Cade, D.C. Greenwood, et al., Dietary fat and breast cancer: comparison of results from food diaries and food-frequency questionnaires in the UK Dietary Cohort Consortium, Am. J. Clin. Nutr. 94 (4) (2011) 1043-1052, http://dx.doi.org/10.3945/ajen.111.015735.

[8] S.Y. Park, L.N. Kolonel, B.E. Henderson, L.R. Wilkens, Dietary fat and breast cancer in postmenopausal women according to ethnicity and hormone receptor status: the Multiethnic Cohort Study, Cancer Prev. Res. (Phila) 5 (2) (2012) 216-228, http://dx.doi.org/10.1158/1940-6207.

[9] E. Cho, D. Spiegelman, D.J. Hunter, W.Y. Chen, M.J. Stampfer, G.A. Colditz, W.C. Willett, Premenopausal fat intake and risk of breast cancer, J. Natl. Cancer Inst. 95 (14) (2003) 1079-1085.

[10] C.A. Gonzalez, E. Riboli, Diet and cancer prevention: Contributions from the European Prospective Investigation into Cancer and Nutrition (EPIC) study, Eur. J. Cancer 46 (14) (2010) 2555-2562, http://dx.doi.org/10.1016 j.ejca.2010.07.025.

[11] D.D. Alexander, L.M. Morimoto, P.J. Mink, K.A. Lowe, Summary and metaanalysis of prospective studies of animal fat intake and breast cancer, Nutr. Res. Rev. 23 (1) (2010) 169-179, http://dx.doi.org/10.1017/ S095442241000003X.

[12] W. Lv, T. Yang, Identification of possible biomarkers for breast cancer from free fatty acid profiles determined by GC-MS and multivariate statistical analysis, Clin. Biochem. 45 (1-2) (2012) 127-133, http://dx.doi.org/10.1016/ j.clinbiochem.2011.10.011.

[13] V. Pala, V. Krogh, P. Muti, V. Chajès, E. Riboli, A. Micheli, M. Saadatian, S. Sieri, F. Berrino, Erythrocyte membrane fatty acids and subsequent breast cancer: a prospective Italian study, J. Natl. Cancer Inst. 93 (14) (2001) 1088-1095.

[14] S. de Assis, G. Khan, L. Hilakivi-Clarke, High birth weight increases mammary tumorigenesis in rats, Int. J. Cancer 119 (7) (2006) 1537-1546.

[15] G. Ion, J.A. Akinsete, W.E. Hardman, Maternal consumption of canola oil suppressed mammary gland tumorigenesis in C3(1)Tag mice offispring, BMC Cancer 10 (2010) 81, http://dx.doi.org/10.1186/1471-2407-10-81.

[16] L. Hilakivi-Clarke, R. Clarke, I. Onojafe, M. Raygada, E. Cho, M. Lippman, A maternal diet high in n-6 polyunsaturated fats alters mammary gland development, puberty onset, and breast cancer risk among female rat offspring, Proc. Natl. Acad. Sci. U.S.A. 94 (17) (1997) 9372-9377.

[17] S. de Assis, A. Warri, M.I. Cruz, O. Laja, Y. Tian, B. Zhang, Y. Wang, T.H. Huang, L. Hilakivi-Clarke, High-fat or ethinyl-oestradiol intake during pregnancy increases mammary cancer risk in several generations of offspring, Nat. Commun. 3 (2012) 1053, http://dx.doi.org/10.1038/ncomms2058.

[18] L. Hilakivi-Clarke, E. Cho, A. Cabanes, S. de Assis, S. Olivo, W. Helferich, M.E. Lippman, R. Clarke, Dietary modulation of pregnancy estrogen levels and breast cancer risk among female rat offspring, Clin. Cancer Res. 8 (11) (2002) 3601-3610.

[19] A.H. Stark, G. Kossoy, I. Zusman, G. Yarden, Z. Madar, Olive oil consumption during pregnancy and lactation in rats influences mammary cancer development in female offspring, Nutr. Cancer 46 (1) (2003) 59-65.

[20] L. Mabasa, K. Cho, M.W. Walters, S. Bae, C.S. Park, Maternal dietary canola oil suppresses growth of mammary carcinogenesis in female rat offspring, Nutr. $\begin{array}{lllll}\text { Cancer } & 65 & \text { (5) (2013) 695-701, http://dx.doi.org/10.1080 }\end{array}$ 01635581.2013 .789539

[21] L. Hilakivi-Clarke, Nutritional modulation of terminal end buds: its relevance to breast cancer prevention, Curr. Cancer Drug Targets 7 (5) (2007) 465-474.

[22] M. Medvedovic, R. Gear, J.M. Freudenberg, J. Schneider, R. Bornschein, M. Yan, M.J. Mistry, H. Hendrix, S. Karyala, S. Heffelfinger, et al., Influence of fatty acid diets on gene expression in rat mammary epithelial cells, Physiol. Genomics 38 (1) (2009) 80-88, http://dx.doi.org/10.1152/physiolgenomics.00007.2009.
[23] S.E. Olivo-Marston, Y. Zhu, R.Y. Lee, A. Cabanes, G. Khan, A. Zwart, Y. Wang, R. Clarke, L. Hilakivi-Clarke, Gene signaling pathways mediating the opposite effects of prepubertal low-fat and high-fat n-3 polynsaturated fatty acid diets on mammary cancer risk, Cancer Prev. Res. (Phila) 1 (7) (2008 Dec) 532-545, http://dx.doi.org/10.1158/1940-6207.

[24] F. de Oliveira Andrade, C.C. Fontelles, M.P. Rosim, T.F. Oliveira, A.P.M. Loureiro, J. Mancini-Filho, M.M. Rogero, F.S. Moreno, S. de Assis, L.F. Barbisan, et al., Exposure to lard-based high-fat diet during fetal and lactation periods modifies breast cancer susceptibility in adulthood in rats, J. Nutr. Biochem. 25 (6) (2014) 613-622, http://dx.doi.org/10.1016/j.jnutbio.2014.02.002.

[25] P.G. Reeves, F.H. Nielsen, G.C. Fahey Jr., AIN-93 purified diets for laboratory rodents: final report of the American Institute of Nutrition ad hoc writing committee on the reformulation of the AIN-76A rodent diet, J. Nutr. 123 (11) (1993) 1939-1951.

[26] K. Ichihara, Y. Fukubayashi, Preparation of fatty acid methyl esters for gasliquid chromatography, J. Lipid Res. 51 (3) (2010) 635-640, http://dx.doi.org/ 10.1194/jlr.D001065.

[27] B. Zhang, Y. Tian, L. Jin, H. Li, Shih. IeM, S. Madhavan, R. Clarke, E.P. Hoffman, J. Xuan, L. Hilakivi-Clarke, et al., DDN: a caBIG ${ }^{\circledR}$ analytical tool for differential network analysis, Bioinformatics 27 (7) (2011 Apr 1) 1036-1038, http:// dx.doi.org/10.1093/bioinformatics/btr052.

[28] N. Bakker, P. Van't Veer, P.L. Zock, Adipose fatty acids and cancers of the breast, prostate and colon: an ecological study. EURAMIC Study Group, Int. J. Cancer 72 (4) (1997) 587-591.

[29] E. Escrich, M. Solanas, R. Moral, R. Escrich, Modularoty effects and molecular mechanisms of olive oil and other dietary lipids in breast cancer, Curr. Pharm. Des. 17 (8) (2011) 813-830.

[30] V. Maillard, P. Bougnoux, P. Ferrari, M.L. Jourdan, M. Pinault, F. Lavillonnière, G. Body, O. Le Floch, V. Chajès, N-3 and N-6 fatty acids in breast adipose tissue and relative risk of breast cancer in a case-control study n Tours, France, Int. J. Cancer 98 (1) (2002) 78-83.

[31] N.S. Kelley, N.E. Hubbard, K.L. Erickson, Conjugated linoleic acid isomers and cancer, J. Nutr. 137 (12) (2007) 2599-2607.

[32] N. Simonsen, P. Van't Veer, J.J. Strain, J.M. Martin-Moreno, J.K. Huttunen, J.F. Navajas, B.C. Martin, M. Thamm, A.F. Kardinaal, F.J. Kok, et al., Adipose tissue omega-3 and omega-6 fatty acid content and breast cancer in the EURAMIC study. European Community Multicenter Study on Antioxidants, Myocardial Infarction, and Breast Cancer, Am. J. Epidemiol. 147 (4) (1998) 342-352.

[33] P. Bougnoux, N. Hajjaji, C. Couet, The lipidome as a composite biomarker of the modifiable part of the risk of breast cancer, Prostaglandins Leukot. Essent. Fatty Acids 79 (3-5) (2008) 93-96, http://dx.doi.org/10.1016/ j.plefa.2008.09.004.

[34] S.E. Olivo, L. Hilakivi-Clarke, Opposing effects of prepubertal low- and high-fat n-3 polyunsaturated fatty acid diets on rat mammary tumorigenesis, Carcinogenesis 26 (9) (2005) 1563-1572.

[35] M. Shahid, T. Tripathi, F. Sobia, S. Moin, M. Siddiqui, R.A. Khan, Histamine, histamine receptors, and their role in immunomodulation: an updated systematic review, Open Immunol. J. 2 (2009) 9-41, http://dx.doi.org/ $10.2174 / 1874226200902010009$

[36] N.A. Cody, V. Ouellet, E.N. Manderson, M.C. Quinn, A. Filali-Mouhim, P. Tellis, M. Zietarska, D.M. Provencher, A.M. Mes-Masson, M. Chevrette, et al., Transfer of chromosome 3 fragments suppresses tumorigenicity of an ovarian cancer cell line monoallelic for chromosome 3p, Oncogene 26 (4) (2007) 618-632.

[37] K. Ruschke, M. Illes, M. Kern, I. Klöting, M. Fasshauer, M.R. Schön, J. Kosacka, G Fitzl, P. Kovacs, M. Stumvoll, et al., Repin 1 maybe involved in the regulation of cell size and glucose transport in adipocyte, Biochem. Biophys. Res. Commun. 400 (2) (2010) 246-251, http://dx.doi.org/10.1016/j.bbrc.2010.08.049.

[38] S. Carrera, S. Cuadrado-Castano, J. Samuel, G.D. Jones, E. Villar, S.W. Lee, S. Macip, Stra6, a retinoic acid-responsive gene, participates in p53-induced apoptosis after DNA damage, Cell Death Differ. 20 (7) (2013) 910-919, http:// dx.doi.org/10.1038/cdd.2013.14.

[39] E.D. Gaier, A. Kleppinger, M. Ralle, J. Covault, R.E. Mains, A.M. Kenny, B.A. Eipper, Genetic determinants of amidating enzyme activity and its relationship with metal cofactors in human serum, BMC Endocr. Disord. 14 (2014) 58, http://dx.doi.org/10.1186/1472-6823-14-58.

[40] D. Bousquet-Moore, X.M. Ma, E.A. Nillni, T.A. Czyzyk, J.E. Pintar, B.A. Eipper, R.E. Mains, Reversal of physiological deficits caused by diminished levels of peptidylglycine alpha-amidating monooxygenase by dietary copper. Endocrinology 150 (4) (2009) 1739-1747, http://dx.doi.org/10.1210/en.20081202.

[41] J. Du, B.P. Keegan, W.G. North, Key peptide processing enzymes are expressed by breast cancer cells, Cancer Lett. 165 (2) (2001) 211-218.

[42] H. Yang, H. Zhou, P. Feng, X. Zhou, H. Wen, X. Xie, H. Shen, X. Zhu, Reduced expression of Toll-like receptor 4 inhibits human breast cancer cells proliferation and inflammatory cytokines secretion, J. Exp. Clin. Cancer Res. 10 (29) (2010 Jul) 92, http://dx.doi.org/10.1186/1756-9966-29-92.

[43] T. Tripathi, M. Shahid, H.M. Khan, M.P. Negi, M. Siddiqui, R.A. Khan, Modulation of in vivo immunoglobulin production by endogenous histamine and H1R and H2R agonists andantagonists, Pharmacol. Rep. 62 (5) (2010) 917-925.

[44] X. Wang, Z. Lu, A. Gomez, G.C. Hon, Y. Yue, D. Han, Y. Fu, M. Parisien, Q. Dai, G. Jia, et al., N6-methyladenosine-dependent regulation of messenger RNA stability, Nature 505 (7481) (2014) 117-120, http://dx.doi.org/ $10.1038 /$ nature 12730 .

[45] S. Blanco, M. Frye, Role of RNA methyltransferases in tissue renewal and pathology, Curr. Opin. Cell Biol. 31C (2014) 1-7, http://dx.doi.org/10.1016/ j.ceb.2014.06.006. 
[46] M.N. Hinman, H. Lou, Diverse molecular functions of Hu proteins, Cell. Mol. Life Sci. 65 (20) (2008) 3168-3181, http://dx.doi.org/10.1007/s00018-0088252-6.

[47] T. Kurosu, N. Ohga, Y. Hida, N. Maishi, K. Akiyama, W. Kakuguchi, T. Kuroshima, M. Kondo, T. Akino, Y. Totsuka, et al., HuR keeps an angiogenic switch on by stabilising mRNA of VEGF and COX-2 in tumour endothelium, Br. J. Cancer 104 (5) (2011) 819-829, http://dx.doi.org/10.1038/bjc.2011.20.

[48] J. Cools, I. Wlodarska, R. Somers, N. Mentens, F. Pedeutour, B. Maes, C. De WolfPeeters, P. Pauwels, A. Hagemeijer, P. Marynen, Identification of novel fusion partners of ALK, the anaplastic lymphoma kinase, in anaplastic large-cell lymphoma and inflammatory myofibroblastic tumor, Genes Chromosom. Cancer 34 (4) (2002) 354-362.

[49] H. Moritake, H. Shimonodan, K. Marutsuka, S. Kamimura, H. Kojima, H. Nunoi, C-MYC rearrangement may induce an aggressive phenotype in anaplastic lymphoma kinase positive anaplastic large cell lymphoma: Identification of a novel fusion gene AL017/C-MYC, Am. J. Hematol. 86 (1) (2011) 75-78, http:// dx.doi.org/10.1002/ajh.21887.

[50] J.B. Zhou, T. Zhang, B.F. Wang, H.Z. Gao, X. Xu, Identification of a novel gene fusion RNF213-SLC26A11 in chronic myeloid leukemia by RNA-Seq, Mol. Med. Rep. 7 (2) (2013) 591-597, http://dx.doi.org/10.3892/mmr.2012.1183.

[51] P.A. Davies, M. Pistis, M.C. Hanna, J.A. Peters, J.J. Lambert, T.G. Hales, E.F. Kirkness, The 5-HT3B subunit is a major determinant of serotonin-receptor function, Nature 397 (6717) (1999) 359-363.

[52] A.J. Thompson, S.C. Lummis, The 5-HT3 receptor as a therapeutic target, Expert Opin. Ther. Targets 11 (4) (2007) 527-540.

[53] Y. Liu, J.K. Wen, L.H. Dong, B. Zheng, M. Han, Krüppel-like factor (KLF) 5 mediates cyclin D1 expression and cell proliferation via interaction with c-Jun in Ang II-induced VSMCs, Acta Pharmacol. Sin. 31 (1) (2010) 10-18, http:// dx.doi.org/10.1038/aps.2009.185.

[54] M. He, M. Han, B. Zheng, Y.N. Shu, J.K. Wen, Angiotensin II stimulates KLF5 phosphorylation and its interaction with c-Jun leading to suppression of p21 expression in vascular smooth muscle cells, J. Biochem. 146 (5) (2009) 683691, http://dx.doi.org/10.1093/jb/mvp115.

[55] C.J. Chen, S.E. Lin, Y.M. Lin, S.H. Lin, D.R. Chen, C.L. Chen, Association of expression of kruppel-like factor 4 and kruppel-like factor 5 with the clinica manifestations of breast cancer, Pathol. Oncol. Res. 18 (2) (2012) 161-168, http://dx.doi.org/10.1007/s12253-011-9422-7.

[56] J.M. Tournier, P. Birembaut, Nicotinic acetylcholine receptors and predisposition to lung cancer, Curr. Opin. Oncol. 23 (1) (2011) 83-87, http:// dx.doi.org/10.1097/CCO.0b013e3283412ea1.

[57] J. Dorszewska, J. Florczak, A. Rózycka, J. Jaroszewska-Kolecka, W.H. Trzeciak, W. Kozubski, Polymorphisms of the CHRNA4 gene encoding the alpha4 subunit of nicotinic acetylcholine receptor as related to the oxidative DNA damage and the level of apoptotic proteins in lymphocytes of the patients with Alzheimer's disease, DNA Cell Biol. 24 (12) (2005) 786-794.

[58] L. Ding C. Niu, Y. Zheng Z. Xiong Y. Liu, J. Lin, H. Sun, K. Huang W. Yang, X. Li, et al., FHL1 interacts with oestrogen receptors and regulates breast cancer cell growth, J. Cell. Mol. Med. 15 (1) (2011) 72-85, http://dx.doi.org/10.1111/ j.1582-4934.2009.00938.x.

[59] D. Blazek, J. Kohoutek, K. Bartholomeeusen, E. Johansen, P. Hulinkova, Z. Luo, P. Cimermancic, J. Ule, B.M. Peterlin, The Cyclin K/Cdk12 complex maintains genomic stability via regulation of expression of DNA damage response genes, Genes Dev. $25 \quad$ (20) (2011) 2158-2172, http://dx.doi.org/ $10.1101 /$ gad.16962311. 